\section{Ritmo e peso silábico na constituição das palavras prosódicas do protocrioulo do Golfo da Guiné}

Rhythm and syllable weight in the prosodic words of the Gulf of Guinea Proto-Creole

Gabriela BRAGA (USP) gabriela.silva@usp.br

Recebido em: 30 de set. de 2019. Aceito em: 30 de dez. de 2019.

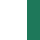

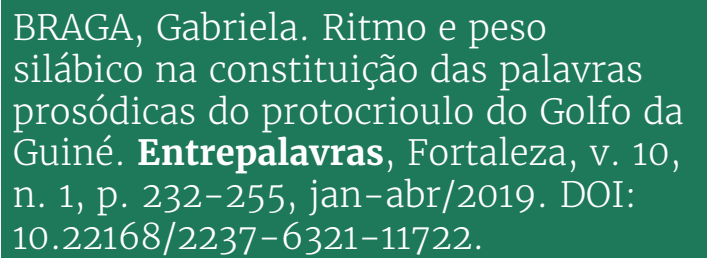

Resumo: O contato entre lusofalantes e populações africanas multilíngues escravizadas na ilha de São Tomé, África Ocidental, a partir do final do século $\mathrm{XV}$, implicou a emergência de uma nova língua: o protocrioulo do Golfo da Guiné (PGG). Posteriormente, o PGG deu origem ao santome, lung' Ie, angolar e fa d'Ambô. A partir da hipótese de que a formação do léxico do PGG teria motivação prosódica, investigamos se fatores como eurritmia associado ao peso silábico (GHINI, 1993) estariam envolvidos na formação de palavra prosódica mínima (VIGÁRIO, 2003). Levando em consideração a produtividade de alguns processos fonológicos que contribuíram para a configuração (em número de sílabas) do léxico do PGG, damos atenção especial ao processo de aglutinação de vogal (O pé (português) $\rightarrow$ *ope "pé"). Tal processo consiste na interpretação de artigos definidos de étimo português como parte da raiz do item lexical seguinte, resultando numa nova palavra prosódica, constituída por duas ou três sílabas. Entretanto, nossos resultados mostram que o sistema fonológico e prosódico do PGG possibilitou a constituição de palavras tanto com mais quanto com menos sílabas do que no étimo português 
participante de sua formação. Assim, as hipóteses levantadas não se sustentam: a aglutinação de vogal inicial, por exemplo, realizou-se em poucos itens do PGG, caracterizando-se como processo marginal na língua. Contudo, é possível que exista uma restrição que evite verbos iniciados por vogais, o que parece dialogar com a restrição encontrada nas línguas edoides (que participaram da formação do PGG), de que palavras nominais sejam iniciadas por segmentos vocálicos.

Palavras-chave: Prosódia. Peso silábico. Proto-crioulo do Golfo da Guiné.

Abstract: The contact between Portuguese speakers and slaved multilingual African populations on São Tome island, West Africa, started at the end of XV century, made a new language emerge: The Proto-Creole of Gulf of Guinea (PGG). After a while, the PGG branched into Santome, Lung'Ie, Angolar and Fa d'Ambô. Starting with the hypothesis that lexicon formation of PGG would have prosodic motivation, we investigate if factors such as uniformity and symmetry towards rhythm associated to syllable weight (GHINI, 1993) would be engaged in the formation of a minimal prosodic word (VIGÁRIO, 2003). Considering how some phonological processes might be productive regarding to lexicon configuration in PGG (according to number of syllables), we give special attention to vowel agglutination (o pé (Portuguese) $\rightarrow{ }^{*}$ op $\varepsilon$ "foot"). Such linguistic process consists in the interpretation of a definite article from Portuguese as part of the stem that follows, resulting in a new prosodic word with two or three syllables. However, our results show that phonological and prosodic system of PGG accepted the formation of words with more syllables as much as with less syllables than there was in Portuguese that took part in PGG formation. Thus, the initial hypothesis doesn't sustain itself: vowel agglutination, for instance, occurred in very few PGG words, showing itself as a hardly occurring process. Nevertheless, there seems to be a restriction about verbs starting with vowels, dialoging with another restriction found in Edoid languages (also involved in PGG formation) which states nouns must start with a vowel segment.

Keywords: Prosody. Syllable weight. Proto-Creole of Gulf of Guinea.

\section{Introdução ${ }^{1}$}

São Tomé e Príncipe, localizado no Golfo da Guiné, eram ilhas desabitadas até a vinda dos colonizadores portugueses, que lá chegaram no final do século XV. O contato entre o português do colonizador e as línguas africanas que vieram com as populações capturadas no continente africano para serem escravizadas fez com que ali emergisse um novo código linguístico: o protocrioulo do Golfo da Guiné (PGG), que depois viria a dar origem às quatro línguas crioulas autóctones: santome, lung'Ie, angolar e fa d'Ambô (FERRAZ, 1979; BANDEIRA, 2017).

Bandeira (2017), visando corroborar o parentesco genético dessas quatro línguas, utiliza o método histórico-comparativo para reconstruir a fonologia do PGG. Ao coletar cerca de 2000 itens do léxico

\footnotetext{
${ }^{1} \mathrm{O}$ presente trabalho foi realizado com apoio da seguinte instituição de fomento à pesquisa: Coordenação de Aperfeiçoamento de Pessoal de Nível Superior - Brasil (CAPES) - Código de Financiamento 001.
} 
V. 10 (1) 232-255 jan-abr 2020

comum às quatro línguas, a autora reúne 536 conjuntos de cognatos, assim como descreve o sistema consonantal, vocálico e silábico desse ancestral comum, apresentando também processos fonológicos que foram responsáveis pela especiação dos protofonemas nos fonemas encontrados nas línguas-filhas.

Um dos processos tratados pela autora é a aglutinação de vogal, em que artigos definidos de étimo português teriam sido interpretados por aquela comunidade de falantes como parte da raiz do item lexical que o seguia, resultando numa nova palavra prosódica constituída por duas ou três sílabas. Alguns autores já se debruçaram sobre o assunto analisando esse processo fonológico nas línguas-filhas, levantando hipóteses de influência das línguas bantas (SCHANG, 2000), e edoides (LADHAMS, 2007) e decalque do português (HAGEMEIJER, 2009b). Bandeira (2017) levanta a hipótese de que a criação dessas palavras poderia ter alguma motivação prosódica. A partir desse argumento, investigamos se fatores como eurritmia (em número de sílabas) associado ao peso silábico e formação de uma palavra prosódica mínima (VIGÁRIO, 2003) poderiam participar do processo de formação do léxico do PGG.

Além dessa breve introdução, apresentamos informações históricas sobre a formação do protocrioulo do Golfo da Guiné, assim como a motivação para sua reconstrução. Em seguida, na seção 2, descrevemos brevemente características gerais do método histórico-comparativo e seus termos específicos, assim como apresentamos o sistema fonológico do PGG (subseção 2.1), que é resultado da reconstrução empreendida por Bandeira (2017). Partimos então, na seção 3, para a descrição do corpus e da metodologia utilizada nesse estudo sobre a influência de características rítmicas e do peso silábico na constituição das palavras prosódicas do PGG, seguida de nossa análise na seção 4 e considerações finais (seção 5).

\section{Formação do protocrioulo do Golfo da Guiné e sua reconstrução}

As primeiras populações não africanas a habitarem as ilhas eram formadas por degredados portugueses, madeirenses e cristãos novos (cf. HLIBOWICKA-WĘGLARZ, 2012, p. 178), além de 2000 crianças judias deportadas do reino de Castela em 1493 por D. João II de Portugal (quinze anos depois, apenas 600 teriam sobrevivido e se casado com africanos, segundo Holm (1989, p. 278)). A maioria da população das ilhas, entretanto, era formada por africanos capturados no então Reino do Benin (hoje sudeste da Nigéria), conforme apontam indícios linguísticos 
e históricos, como laços comerciais e diplomáticos existentes entre os portugueses e o Reino do Benin no final do século XV (HAGEMEIJER, 2009a, p. 2). Parte desses cativos permanecia na ilha como escravos de casa, enquanto outros eram comercializados como escravos de resgate.

De acordo com a hipótese mais aceita (FERRAZ, 1979; HAGEMEIJER, 2009a; BANDEIRA, 2017, entre outros), um código emergencial teria se desenvolvido na ilha de São Tomé nos anos iniciais de sua ocupação - fase de habitação, que compreende o período de 1493 até o início do desenvolvimento comercial da produção de açúcar, em 1515 (GARFIELD, 1992; HAGEMEIJER, 2009a) - e se nativizado rapidamente entre os descendentes da primeira geração de africanos escravizados, dando origem ao protocrioulo do Golfo da Guiné (PGG).

A falta de embarcações para o transporte dos escravos de resgaste ao seu destino final (Europa, Caribe e Brasil) fazia com que estes chegassem a passar meses em São Tomé, contribuindo assim para o processo de crioulização. Além disso, o desequilíbrio demográfico (número de lusofalantes menor do que o de cativos multilíngues), o contexto de confinamento e isolamento geográfico e a falta de uma atividade econômica de envergadura (acarretando num maior contato entre essas duas populações) fizeram com que os vinte e dois anos da fase de habitação fossem um período propício para a emergência desse novo código linguístico, o PGG (HAGEMEIJER, 2009a).

A partir de 1515, tem início a fase de plantação, marcada pela exploração intensiva de mão de obra escrava, o que alterou a dinâmica social e econômica existente na ilha até então. Além disso, São Tomé passa a ser um grande entreposto de comércio de escravos no Atlântico, de onde eram enviados para a feitoria da Mina, para Portugal e para as plantações de cana de açúcar nas Américas (cf. HLIBOWICKA-WĘGLARZ, 2012, p. 178-179).

Nesse momento, acredita-se que o PGG já estivesse desenvolvido e, devido à movimentação de populações para outras localidades, tenha passado por especiações que resultaram nas quatro línguas crioulas do Golfo da Guiné que surgem em diferentes cenários, a saber: (a) santome (ou forro), nos núcleos de colonização da ilha de São Tomé; (b) lung'Ie, que se desenvolveu na ilha do Príncipe, (c) fa d'Ambô², na ilha de Ano Bom; e (d) angolar, desenvolvido no contexto quilombola, em comunidades formadas por ex-escravizados ao sul da ilha de São Tomé.

${ }^{2}$ O fa d'Ambô é uma das línguas-filhas do protocrioulo do Golfo da Guiné que se desenvolveu na ilha de Ano Bom, hoje território pertencente à Guiné Equatorial. 
V. $10(1)$

$232-255$

jan-abr

2020

Dessa forma, a partir da hipótese de que haveria um ancestral comum às línguas crioulas do Golfo da Guiné, Bandeira (2017) reuniu 2000 itens do léxico comum entre as quatro línguas-filhas (santome, lung'Ie, fa d'Ambô e angolar). Após observar as regularidades e subregularidades dessas quatro línguas, tanto nos últimos anos quanto em estados pretéritos, a autora descreveu e analisou a fonologia dessas línguas, visando à reconstrução fonológica do PGG. Como resultado, Bandeira (2017) apresenta 536 conjuntos de cognatos, assim como características fonológicas dessa protolíngua: seu sistema consonantal, vocálico, silábico e acentual, além de processos fonológicos que teriam participado da constituição das 536 protoformas do PGG que foram reconstruídas.

\section{Reconstrução fonológica e o PGG reconstruído}

A reconstrução fonológica do PGG foi realizada através do uso do método histórico-comparativo, que tem como objetivo recuperar o máximo possível a língua ancestral, a protolíngua ${ }^{3}$, através da comparação de itens que compartilham traços fonêmicos e semânticos nas línguas descendentes.

O método histórico-comparativo é muito utilizado para a reconstrução da fonologia de uma língua, visto que este é um sistema fechado, possuindo um número finito de elementos. A partir da reconstrução dos fonemas da protolíngua, é possível realizar a reconstrução de itens do seu vocabulário.

Para a aplicação do método histórico-comparativo, é necessário reunir cognatos. Um cognato é uma palavra que é aparentada a outra nas línguas-irmãs justamente por terem sido herdadas de uma língua ancestral comum. Através da comparação de cognatos é possível verificar os reflexos nas línguas-filhas, ou seja, o descendente do "som" existente na língua ancestral, e propor qual seria o fonema ancestral na protolíngua que está sendo reconstruída.

A aplicação do método histórico-comparativo para a realização da reconstrução fonológica é realizada através de etapas (cf.

\footnotetext{
${ }^{3}$ Campbell (1998, p. 111-112) apresenta a descrição de conceitos e termos técnicos utilizados na aplicação do método histórico-comparativo. Segundo o autor, uma protolíngua é (i) uma língua ancestral outrora falada da qual descendem outras línguas; (ii) a língua reconstruída pelo método histórico comparativo que representa a língua ancestral da qual as línguas que estão sendo comparadas descendem; sendo ideal que (i) e (ii) coincidam, significando que a aplicação do método tenha sido eficaz. Línguas-irmãs, por sua vez, são aquelas que são descendentes de um ancestral comum, pertencendo à mesma família.
} 
CAMPBELL, 1998, p. 112-132), de modo sistemático, proporcionando uma checagem dos itens reconstruídos à medida que a reconstrução do sistema fonológico da protolíngua avança.

Bandeira (2017), para a reunião de cognatos, fez uso de literatura recentemente publicada sobre as línguas-filhas (FERRAZ, 1979; ARAUJO; HAGEMEIJER, 2013, para o santome; MAURER, 2009; AGOSTINHO, 2015, para o lung'Ie; MAURER, 1995, para o angolar; e BARRENA, 1957; SEGORBE, 2007, para o fa d'Ambô), de alguns estudos publicados no século XIX - que apresentavam certa limitação descritiva e divergências nas notações (cf. Bandeira (2017, p. 28), para a relação dos itens consultados) - e especialmente da coleta de dados in loco.

Ao final da reconstrução do PGG, Bandeira (2017) apresenta sistema consonantal, vocálico e silábico dessa protolíngua:

Quadro 1 - Fonemas consonantais do PGG

\begin{tabular}{|c|c|c|c|c|c|c|}
\hline & Labial & $\begin{array}{l}\text { Labio- } \\
\text { Dental }\end{array}$ & Alveolar & Palatal & Velar & $\begin{array}{l}\text { Labio- } \\
\text { Velar }\end{array}$ \\
\hline Oclusivo & $* \mathrm{p} * \mathrm{~b}$ & & $* \mathrm{t} * \mathrm{~d}$ & & $* \mathrm{k} * \mathrm{~g}$ & $* g b$ \\
\hline Fricativo & & $*_{\mathrm{f}} *_{\mathrm{V}}$ & $*_{\mathrm{S}} *_{\mathrm{Z}}$ & & & \\
\hline Nasal & $* \mathrm{~m}$ & & $* \mathrm{n}$ & $*_{\mathrm{n}}$ & & \\
\hline Lateral & & & $* 1$ & & & \\
\hline Vibrante & & & $*_{r}$ & & & \\
\hline Aproximante & $*_{\mathrm{W}}$ & & & $* \mathrm{j}$ & & \\
\hline
\end{tabular}

Quadro 2 - Vogais do PGG

$\begin{array}{llll} & \text { Anterior } & \text { Central } & \text { Posterior } \\ \text { Alta } & *_{\mathrm{i}} & & *_{\mathrm{u}} \\ \text { Média-alta } & *_{\mathrm{e}} & & *_{\mathrm{o}} \\ \begin{array}{l}\text { Média- } \\ \text { baixa }\end{array} & *_{\varepsilon} & *_{0} \\ \begin{array}{l}\text { Baixa } \\ \text { Fonte: Bandeira (2017, p. 304). }\end{array} & *_{\mathrm{a}} & \end{array}$

De acordo com a autora, o PGG possui sete tipos de estrutura silábica: $*_{\mathrm{V}},{ }^{*} \mathrm{VC},{ }^{*} \mathrm{C},{ }^{*} \mathrm{CV},{ }^{*} \mathrm{CVC},{ }^{*} \mathrm{CCV}$ e ${ }^{*} \mathrm{CCVC}$. A posição de núcleo silábico pode ser preenchida por uma vogal simples (i, e, $\varepsilon$, a, o, o, u) ou por uma consoante nasal $(* N)$. Na sílaba em que a nasal ocupar o núcleo não são aceitos elementos no onset e/ou na coda. Quanto à posição de 
V. $10(1)$

$232-255$

jan-abr

2020

onset, tanto em início quanto meio de palavra, ela pode ser ocupada pelas consoantes $* \mathrm{~b}, *_{\mathrm{p}}, *_{\mathrm{t}}, *_{\mathrm{d}}, *_{\mathrm{k}}, *_{\mathrm{g}}, *_{\mathrm{m}}, *_{\mathrm{n}}, *_{\mathrm{n}}, *_{\mathrm{l}}, *_{\mathrm{f}}, *_{\mathrm{v}}, *_{\mathrm{s}}, *_{\mathrm{z}}$, $*_{\mathrm{r}}, *_{\mathrm{w}}$ e $*_{\mathrm{j}}$. Além disso, são admitidos onsets complexos cujo segundo elemento seja uma consoante aproximante $\left({ }^{*} \mathrm{w}\right.$ ou $\left.* \mathrm{j}\right)$ ou a consoante lateral $* \mathrm{l}$ se o primeiro elemento foi $* \mathrm{~b}, *_{\mathrm{p}}$, $* \mathrm{t}, *_{\mathrm{d}}, *_{\mathrm{k}}, *_{\mathrm{g}}, *_{\mathrm{m}}, *_{\mathrm{n}}, *_{\mathrm{f}}$ ou *v. Já na posição de coda, são aceitos as consoantes $* \mathrm{~N}$ e $* \mathrm{~S}$, e as consoantes aproximantes $*_{\mathrm{w}} \mathrm{e} * \mathrm{j}$, assim como as líquidas $* \mathrm{r}$ e $* \mathrm{l}$. Dessa forma, itens como $*$ NganaN 'galinha' são formados por três sílabas:

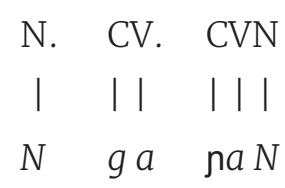

A autora também apresenta processos fonológicos que teriam acarretado alterações dos protofonemas na formação do sistema fonológico das línguas-filhas.

\section{Aglutinação de artigo e PGG}

Nas línguas crioulas autóctones do Golfo da Guiné, o processo de aglutinação ${ }^{4}$ de vogal em início de palavra acontece no contexto em que artigos definidos de étimo português teriam sido interpretados pela nova comunidade de falantes como parte da raiz do item lexical que o seguia, resultando numa nova palavra prosódica, já em PGG, composto por uma forma equivalente de uma palavra prosódica de étimo português com seu proclítico adjungido (além da aplicação de outras regras fonotáticas e fonológicas do novo sistema linguístico que ali se formava).

- Exemplos de aglutinação de artigo

(1) $O$ pé (português) $\rightarrow$ *ope 'pé'

(2) 0 pó (português) $\rightarrow$ *opo 'pó, poeira'

Entretanto, Bandeira (2017) verificou que na formação do PGG esse foi um processo marginal, visto que apenas sete protoformas foram reconstruídas com o artigo definido adjungido ao nome: *are 'rei', *omali

\footnotetext{
${ }^{4}$ Fazemos uso do termo aglutinação por este ser utilizado por outros autores de estudos sobre as línguas do Golfo da Guiné para tratarem do mesmo processo abordado neste artigo. Portanto, neste artigo, o termo aglutinação não corresponde ao processo fonológico em que duas vogais são fundidas (crase).
} 


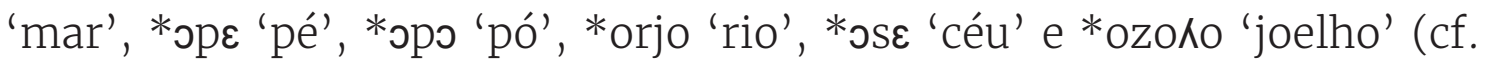
BANDEIRA, 2017, p. 354). Ademais, Bandeira (2017) argumenta que só ocorreu nos casos em que poderia haver alguma motivação para a criação de uma palavra dissilábica ou trissilábica, sendo assim engatilhado por questões prosódicas ou mesmo restrições silábicas.

A partir desse argumento, levantamos a hipótese de que fatores como eurritmia (em número de sílabas) associado ao peso silábico e formação de uma palavra prosódica mínima (VIGÁRIO, 2003) poderiam participar do processo de formação do léxico do PGG.

Schang (2000) discute o processo de aglutinação de vogal inicial nos crioulos do Golfo da Guiné adotando a proposta de que tal processo se daria devido à influência das classes nominais das línguas bantas. Embora o autor considere que a influência das classes nominais bantas não podem ser responsáveis pela aglutinação das vogais iniciais [i-] e [u-], pois a sobreposição semântica com a respectiva classe nominal não pode ser recuperada, ele assume que o léxico do português que tenha participado da constituição do lung'Ie tenha relexificado massivamente o léxico do quimbundo, sendo tal vocabulário de étimo português incorporado em uma classe de substantivo (a de empréstimos) e passado a apresentar como prefixo o artigo definido do quimbundo, [o-]. Ademais, Schang (2000) sugere que a proximidade entre o artigo definido em português e em quimbundo pode ter resultado no padrão observado em lung' Ie (em que a aglutinação da vogal [u-] apareceria em muitos itens lexicais), tais como em: uratu 'rato', uremu 'remo', uventu 'vento', ufew 'ferro', uman 'mão', upa 'pau' e ubwê 'boi' . Entretanto, esperar-se-ia que a função semântica do artigo aglutinado ao item lexical o acompanhasse, o que não ocorre.

Além disso, os dados linguísticos mostram que o lung'Ie apresenta muito mais traços de línguas do delta do Níger, seu substrato principal, do que de línguas bantas, além das evidências históricas de que populações falantes de línguas bantas só tenham chegado à ilha num período posterior à formação do crioulo. Hagemeijer (2009b) argumenta ainda que o quimbundo teve uma participação como língua de adstrato e em um estágio em que os crioulos já começavam a se cristalizar.

Hagemeijer (2009b), ao se deparar com o processo de aglutinação de vogal em santome, lung'Ie, angolar e fa d'Ambô, assume que este teria ocorrido ainda no PGG e busca verificar o que o teria motivado. Embora o autor assuma o santome como a continuação direta do PGG ao analisar dados das quatro línguas filhas, defende em sua análise que, no 
V. 10 (1) $232-255$ jan-abr 2020 período de formação do PGG, teria havido um maior acesso à língua-alvo (o português), visto que em São Tomé havia uma sociedade de habitação, e, portanto, o processo de aglutinação de vogal inicial seria o resultado do decalque fonético do artigo com o item lexical, na tentativa de aquisição do português, motivado pela restrição das línguas edoides de que os substantivos devem ser iniciados por vogais.

Ladhams (2007), por sua vez, analisando o mesmo processo fonológico nas quatro línguas do Golfo da Guiné, faz um levantamento histórico dos locais e da época em que os portugueses capturaram os escravos na costa do continente africano e os levaram para São Tomé, Príncipe e Ano Bom, buscando entender se o substrato teria influenciado na ocorrência do processo e quais línguas fariam parte dele. Em seu levantamento de dados, o autor encontrou 15 itens em santome em que o artigo aparece aglutinado, 14 em fa d'Ambô, 3 em angolar e 88 em lung'Ie.

Segundo o autor, no início do povoamento de São Tomé e, portanto, momento da formação do PGG, ainda na sociedade de habitação, as populações africanas eram procedentes das regiões dos rios Real e Forcados, mas em especial do Reino do Benin, cuja população correspondia ao grupo etnolinguístico edo: o porto de Hugató, que dava acesso a ele, foi uma feitoria portuguesa de 1487 a 1507. No século XVI, o reino do Benin também governava a área ocupada pelos itsekiri. Segundo Ladhams (2007, p. 6), populações dessa etnia, cuja língua é intimamente relacionada ao iorubá, eram vendidas como escravos pelo grupo etnolinguístico edo. O tráfico de escravos também era intenso no rio Congo (porto de Mpinda), local que tem sido destacado como a maior fonte de escravos para as ilhas do Golfo da Guiné na década de 1530. Contudo, não há menção de que tais escravos tivessem permanecido nas ilhas por muito tempo.

Segundo Ladhams (2007, p. 7), o input de línguas bantas só teve início com a sociedade de plantação, em que o PGG já teria se formado e sido levado para a ilha do Príncipe e de Ano Bom (BANDEIRA, 2017). O alto número de itens lexicais que apresentam aglutinação de vogal inicial em lung'Ie seria decorrente do contrato exclusivo entre o reino do Benin e a ilha do Príncipe: pelo período de 1514-1518, escravos eram levados da região do rio Forcados e de Hugató (área governada pelo reino do Benin) diretamente para a ilha do Príncipe. Dessa forma, o lung'Ie, e não o PGG, teria recebido um intenso input edo, o que justificaria a maior quantidade de itens que apresentam aglutinação de vogal inicial. 
Nossa análise, portanto, volta-se para a protolíngua que teria dado origem às quatro línguas crioulas do Golfo da Guiné e busca verificar se o processo de aglutinação de vogal inicial, embora não pareça ter sido tão robusto no PGG quanto no lung'Ie, teria uma motivação prosódica, como fatores de eurritmia, associada ao peso silábico, na formação de uma palavra prosódica mínima.

Ademais, analisamos se o léxico de origem portuguesa, ao ser interpretado pelas regras fonotáticas e prosódicas do PGG em formação, passaria a um maior número de sílabas, através de epêntese vocálica na dissolução de onsets complexos e ressilabificação de codas, ou a um menor número de sílabas, através do apagamento de segmentos ou sílabas inteiras, trazendo pistas sobre uma motivação rítmica inerente ao novo sistema linguístico (o PGG).

\section{Corpus e metodologia}

Para nossa análise, utilizamos os 536 itens reconstruídos por Bandeira (2017) para o protocrioulo do Golfo da Guiné. No estudo desenvolvido pela autora, os itens reconstruídos aparecem organizados por campo semântico assim como numerados ao longo do texto. Nosso corpus, portanto, é formado por essas 536 protoformas, em que são encontrados nomes, adjetivos, verbos, preposições, etc., em vinte e sete campos semânticos: alimentos e bebidas em geral; anatomia animal e termos relacionados; anatomia humana e termos relacionados; animais e termos relacionados; conceitos abstratos; cores; crustáceos, peixes e termos relacionados; doenças e termos relacionados; evento; insetos; humanos; lugares e construções em geral; metais; natureza; ofícios; parentesco e termos relacionados; pronomes e outros elementos gramaticais; qualificadores; quantitativos; tempo; espiritualidade; fauna e relacionados; localização; utensílios e artefatos; vestuário; topônimos e nomes sem classificação (cf. BANDEIRA, 2017).

Nossa metodologia consistiu em, inicialmente, separar as 536 protoformas em palavras simples e compostas. Em seguida, agrupamos as palavras simples de acordo com o número de sílabas, seguindo a descrição do molde silábico proposto por Bandeira (2017) para o PGG, assim como das restrições fonotáticas postuladas, conforme descrito na seção anterior. Após esse procedimento, verificamos qual caminho teria sido mais produtivo na formação dos itens lexicais desse novo sistema linguístico: (i) itens com um maior número de sílabas, através 
V. 10 (1) $232-255$ jan-abr 2020

de aglutinação de vogal em início de palavra, epêntese vocálica na dissolução de onsets complexos e ressilabificação de codas, ou (ii) itens como um menor número de sílabas, através do apagamento de segmentos ou mesmo de sílabas inteiras.

\section{Análise de dados}

Para nossa análise, levamos em consideração o conceito de eurritmia proposto por Ghini (1993), adaptado para palavras prosódicas, assim como a definição de palavra prosódica mínima proposta por Vigário (2003), visando compreender se esses fatores prosódicos estariam envolvidos no comprimento (em número de sílabas) dos itens lexicais do PGG que então se formava.

Ghini (1993, p. 56) apresenta um estudo para o italiano em que argumenta que questões de eurritmia estariam envolvidas no fraseamento das sentenças em sintagmas fonológicos. Resumidamente, o autor assume que haveria um princípio de uniformidade e comprimento médio que regeria a formação do sintagma fonológico, sendo este, numa velocidade média de elocução, formado por duas palavras prosódicas. Se aplicássemos o princípio de eurritmia para constituintes abaixo do sintagma fonológico, poderíamos assumir que uma palavra prosódica média seria idealmente formada por duas sílabas, ou seja, um pé métrico.

Vigário (2003, p. 263), por sua vez, ao definir as condições de boa-formação de uma palavra prosódica (para o português europeu), assume que uma palavra prosódica mínima possui apenas um único acento primário (lexical), sendo considerada como uma palavra prosódica mínima aquela que domina o nível prosódico imediatamente inferior (ou seja, o pé métrico).

Embora esses estudos não tratem do PGG, podemos verificar se o que está postulado por esses autores para suas respectivas línguas poderia se aplicar ao protocrioulo, tratando-se, portanto, de assunções sobre aspectos prosódicos das línguas naturais.

Dessa forma, conforme já apontado, as 536 protoformas do PGG foram agrupadas nas seguintes categorias: monossílabos, dissílabos, trissílabos, polissílabos e palavras compostas (formadas por duas palavras prosódicas). Os resultados quantitativos desse agrupamento podem ser vistos na Tabela 1: 
Tabela 1 - Distribuição de protoformas do PGG por número de sílabas

\begin{tabular}{cc}
\hline Número de sílabas $(\boldsymbol{\sigma})$ & Protoformas \\
Monossílabos $(1 \sigma)$ & $20(3,73 \%)$ \\
Dissílabos $(2 \sigma)$ & $361(67,35 \%)$ \\
Trissílabos $(3 \sigma)$ & $125(23,32 \%)$ \\
Polissílabos $(4 \sigma)$ & $13(2,43 \%)$ \\
Palavras compostas & $17(3,17 \%)$ \\
TOTAL & $536(100 \%)$ \\
\hline Fonte: Elaborada pelas autoras.
\end{tabular}

Visando estudar como seria a constituição de uma palavra prosódica mínima em PGG, não nos deteremos na análise das palavras compostas, visto que estas são formadas por duas palavras prosódicas. Focaremos, portanto, nossa análise nas palavras simples, que corresponderiam às palavras prosódicas do PGG.

Numa análise quantitativa global, verificamos que a maioria das protoformas do PGG são constituídas por duas sílabas (67,35\%), o que nos leva a pensar que esse talvez seja um comprimento privilegiado na formação de itens lexicais do PGG. Em (3) apresentamos exemplos de palavras de étimo português que passaram a um maior número de sílabas (3.a, 3.b) e a um menor número de sílabas (3.c, 3.d) ao incorporarem ao léxico do PGG:

(3)

(a) pó> *opo

(b) favor $>*$ favolo

(c) velho $>*_{v \varepsilon}$

(d) caroço $>*$ klosu

No conjunto de exemplos (3), embora o exemplo em (3.a) ilustre o processo de aglutinação de vogal em início de palavra - o étimo português, então monossílabo, é interpretado pela gramática do PGG como uma palavra constituída por duas sílabas - podemos ver que o input de dissílabos nem sempre resultou em palavras formadas por duas sílabas em PGG: os exemplos (3.b) e (3.c), embora dissílabos no étimo português, ao serem interpretados pela gramática do PGG passaram a ser constituídos por três e uma sílaba, respectivamente. O exemplo em (3.d), por sua vez, ilustra os itens lexicais constituídos por três sílabas que, ao serem interpretados pelas regras fonológicas do PGG, passaram 
V. 10 (1)

$232-255$

jan-abr

2020

a ser constituídos por duas sílabas (não estando claro se a condição eurrítmica teria interferência nesse desdobramento).

Entretanto, assim como verificado por Bandeira (2017, p. 354), não foram muitas as palavras de étimo português que passaram por processos fonológicos, como a aglutinação de vogal, para adequaremse a essa constituição lexical (dissílabos). Ao nos debruçarmos sobre as protoformas dissilábicas (361 itens) verificamos que 233 delas $(64,54 \%)$ já eram constituídas por duas sílabas em seu étimo português. Dessa forma, o alto índice de protoformas dissílabas pode estar mais relacionado à constituição do input português que tenha participado na formação do PGG do que a regras fonotáticas dessa protolíngua.

Com relação aos trissílabos, que correspondem a 23,32\% das protoformas reconstruídas (125 itens), verificou-se que 92 deles $(73,6 \%)$ também apresentavam essa constituição em seu étimo português (excluímos da análise as protoformas que provavelmente possuem como étimo as línguas africanas que participaram da formação do PGG, como as línguas edoídes), corroborando o que foi assumido para o alto índice de protoformas formadas por duas sílabas.

Em nosso corpus de 536 protoformas, ao analisarmos a constituição dos itens ainda de étimo português, verificamos que 22 deles eram constituídos por uma única sílaba. Entretanto, na formação do PGG, apenas 9 mantiveram-se monossílabos. Os outros 13 itens (monossílabos no étimo português), ao serem interpretados pelo novo sistema linguístico que surgia, passaram a ser constituídos por duas sílabas, caminhando em direção à hipótese de que o PGG possuiria regras que beneficiaram a criação de palavras dissílabas. O conjunto de exemplos em (4) ilustra itens lexicais monossílabos no étimo português que em PGG são constituídos por uma ou duas sílabas:

(4)

(a) pão $>$ *poN

(b) ver $>*$ be

(c) $\mathrm{mel}>* \mathrm{~m} \varepsilon \mathrm{l} \varepsilon$

(d) flor $>*$ floli

Em (4), (4.a) e (4.b) representam os itens lexicais monossílabos em seu étimo português que permaneceram sendo constituídos por uma única sílaba em PGG. O exemplo (4.a), entretanto, pode ter entrado no PGG tal como era realizado no étimo português na época: de acordo com 
Teyssier (2014 [1980], p. 55-56) as palavras do português no século XIV que possuíam primitivamente a terminação '-an' e '-on' convergiram para a terminação '-ão' por volta de 1500, sendo essa uma mudança advinda do sul e centro de Portugal e que atingiu só uma parte do norte do país. Por ser uma mudança em transição na época da formação do PGG, assim como não se pode afirmar que a origem dos falantes de português que ofereceram o input da língua eram oriundos do centrosul de Portugal, é muito provável que palavras como 'pão' tenham participado do input sendo realizadas com a terminação '-on'. Dessa forma, *poN não teria sofrido mudanças fonotáticas ao ser inserido no léxico do PGG. O exemplo em (4.b), por sua vez, embora mantenha a constituição monossilábica, mostra o apagamento do rótico em posição de coda. Por se tratar de um verbo, outras regras podem ter participado na sua interpretação pela gramática do PGG. Já em (4.c) e (4.d) vemos exemplos de itens que, ao serem interpretados pelas regras fonológicas e fonotáticas do PGG, entraram na língua como itens constituídos por duas sílabas. Ambos parecem refletir uma restrição à coda, que seria desfeita através de paragoge e ressilabificação, embora Bandeira (2017) afirme que nessa posição são aceitas as consoantes líquidas *r e *l.

Separamos então as protoformas em dois grupos, (i) verbos e (ii) não verbos (substantivos, adjetivos, pronomes, numerais, etc.), para verificar se a classe gramatical poderia estar relacionada ao caminho adotado pelo PGG para a constituição de seus itens lexicais quanto ao comprimento em número de sílabas e possíveis restrições eurrítmicas.

(i) Verbos

Levando em consideração os 27 campos semânticos estabelecidos por Bandeira (2017), consideraremos como 'verbos' os itens lexicais agrupados sob a etiqueta 'Evento' (cf. BANDEIRA, 2017, p. 377-387). De imediato, chama-nos a atenção que das 126 protoformas verbais apenas uma inicia-se com vogal: *obliga 'obrigar'. Dessa forma, o processo de aglutinação de vogal inicial parece não ter sido produtivo nos verbos do PGG. Pelo contrário, com exceção daquele mencionado acima, todos os verbos cujos inputs no étimo português eram iniciados por vogal sofreram apagamento da sílaba inicial, de segmento vocálico (permanecendo na sílaba apenas a consoante nasal) ou metátese (em menor escala) ao serem interpretados pela gramática do PGG: 
V. 10 (1)

$232-255$

jan-abr

2020
(5)

(a) 'amarrar' $>*$ mara

(b) 'abandonar' $>*$ baNdona

(c) 'esfregar' $>*$ flega

(d) 'encontrar' > *koNtla

(e) 'engomar' > *Ngoma

(f) 'escrever' $>*$ sikleve

Conforme demonstram os exemplos em (5), os verbos iniciados por vogal no étimo português, ao serem interpretados pela gramática do PGG, parecem ter seguido três caminhos: apagamento total da sílaba, fosse ela constituída unicamente por vogal (5.a e 5.b), ou tendo sua coda preenchida por uma consoante fricativa (5.c) ou consoante nasal silábica (5.d); apagamento apenas da vogal (5.e) em alguns casos em que a posição de coda estivesse preenchida pela consoante nasal, visto que esta pode constituir uma sílaba independente; e metátese (5.f), se a posição de coda estivesse preenchida, passando de uma sílaba VC para a estrutura CV.

Das 126 protoformas verbais, 31 eram iniciadas por vogal no étimo português. Dessas, 16 seguiram o padrão exemplificado em (5.a) e (5.b), em seis itens verbais encontrou-se o padrão exposto em (5.c), quatro se comportaram como o exemplo em (5.d), duas protoformas verbais correspondem aos que foi demonstrado em (5.e) e duas como ilustra o exemplo em (5.f). O tipo de segmento ocupando a posição de coda no étimo português desencadeou resoluções diferentes em PGG: como essa protolíngua aceita que a consoante nasal forme uma sílaba independente, sílabas VC cuja posição de coda fosse ocupada pela consoante nasal tiveram ora apenas a vogal apagada (como em 5.e) ora toda a sílaba inicial sendo apagada (como ilustra 5.d); caso a posição de coda fosse preenchida por outra consoante, observou-se que, na maioria dos casos, a sílaba por inteiro sofreu apagamento (5.c). Em menor proporção, entretanto, sílabas VC sofreram metátese (5.f), embora esse parecer ter sido um processo marginal.

Dessa forma, a constituição das protoformas verbais, em relação ao número de sílabas, não foi privilegiada pelo processo de aglutinação de vogal inicial. Entretanto, o apagamento silábico parece ter tido uma participação expressiva. Na Tabela 2 é apresentada a distribuição das protoformas verbais por número de sílabas: 
Tabela 2 - Distribuição de protoformas verbais do PGG por número de sílabas

\begin{tabular}{cc}
\hline Número de sílabas $(\boldsymbol{\sigma})$ & Verbos \\
Monossílabos $(1 \sigma)$ & $5(3,97 \%)$ \\
Dissílabos $(2 \sigma)$ & $106(84,13 \%)$ \\
Trissílabos $(3 \sigma)$ & $12(9,52 \%)$ \\
Polissílabos $(4 \sigma)$ & $1(0,79 \%)$ \\
Palavras compostas & $2(1,59 \%)$ \\
TOTAL & $126(100 \%)$ \\
\hline Fonte: Elaborada pelas autoras.
\end{tabular}

De acordo com os dados apresentados na Tabela 2, 84,13\% das protoformas verbais do PGG apresentam constituição dissilábica. Dessas 106 protoformas verbais constituídas por duas sílabas, 65 (61,32\%) já apresentavam essa constituição no étimo português. No que diz respeito às outras 41 protoformas verbais dissilábicas, verificamos que 23 eram trissílabos iniciados em vogal que sofreram apagamento, 9 eram trissílabos não iniciados por vogal no input português, mas que sofreram apagamento dentro da palavra (como *dlete 'derreter' e *simja 'plantar/ semear') e apenas um era monossílabo (*kele 'crer'). Além disso, em 9 protoformas verbais não é possível ter certeza qual seria o étimo.

Em segundo lugar, aparecem as protoformas verbais constituídas por três sílabas, com 9,52\%. Protoformas verbais constituídas por uma e quatro sílabas são marginais (3,97\% e 0,79\%, respectivamente).

Podemos conjecturar, portanto, uma preferência por verbos constituídos por duas sílabas. Contudo, a maior restrição para a constituição dos verbos parece ser que estes não deveriam ser iniciados por vogais e privilegiando a estrutura CV (apenas 13 protoformas verbais apresentam onsets complexos na sílaba inicial).

(ii) Não verbos

Quanto às protoformas consideradas para a análise da categoria não verbal, utilizamos aquelas sob as etiquetas semânticas 'Alimentos e bebidas em geral', 'Anatomia animal e termos relacionados', 'Anatomia humana e termos relacionados', 'Animais e termos relacionados', 'Conceitos abstratos', 'Cores', 'Crustáceos, peixes e termos relacionados', 
V. 10 (1)

$232-255$

jan-abr

2020

'Doenças e termos relacionados', 'Insetos', 'Humanos', 'Lugares e construções em geral', 'Metais', 'Natureza', 'Ofícios', 'Parentesco e termos relacionados', 'Qualificadores', 'Quantitativos', 'Tempo', 'Espiritualidade', 'Fauna e relacionados', 'Localização', 'Utensílios e artefatos', 'Vestuário', 'Topônimos', e 'nomes sem classificação' (Cf. BANDEIRA, 2017), que totalizam 395 itens. Descartamos os itens anotados por Bandeira (2017) como 'Evento', tratados no tópico anterior.

Segundo Hagemeijer (2009b), a aglutinação de vogal inicial teria afetado itens então monossilábicos em sua etimologia e também se espalhado para itens constituídos por duas sílabas no étimo português. O autor postula que a ocorrência do processo se daria como resultado de um reflexo etimológico dos artigos definidos (em português), que teriam se tornado semanticamente apagados e generalizados para algo além da marcação de gênero e número (função semântica dos artigos na língua portuguesa). A partir disso, segundo o autor, o tipo de vogal aglutinada seria resultado do gênero do étimo português e de um sistema de harmonia ATR com a raiz do item lexical.

Entretanto, verificando a constituição fonotática das protoformas nominais, verificamos que, dos 395 itens analisados, apenas $45(11,39 \%)$ apresentam vogal inicial. Desses, 38 possuem a sílaba inicial constituída apenas pela vogal, três apresentam a posição de coda preenchida pela consoante nasal, três pela consoante lateral *1 e apenas um item apresenta como sílaba inicial uma vogal seguida da consoante fricativa $*_{s}$. Assim, não parece existir uma obrigatoriedade de que as protoformas nominais apresentem uma vogal em início de palavra, o que refuta a assunção de Hagemeijer (2009b) de que o processo de aglutinação seria decorrente de influência das línguas edoídes, em que todas as palavras nominais devem ser iniciadas por vogais, embora também não pareça haver uma restrição que impeça que tais itens apresentem uma vogal inicial.

Quanto à produtividade do processo de aglutinação de vogal inicial, dos 45 itens nominais iniciados por vogal no PGG, verificouse que apenas 7 (15,56\%) parecem ser o resultado desse processo, em que a gramática do PGG teria interpretado o proclítico como parte da palavra prosódica do étimo português. Do restante dos itens nominas do PGG que se iniciam por vogal, 31 (68,89\%) mantiveram a vogal já existente no étimo português, 6 (13,33\%) são de procedência edoide e mantiveram a vogal inicial presente no étimo (*akere 'sapo' > akere, *ize 'camarão' > ize, *idu 'piolho' > idu, *obo 'floresta' > ogbo, *igligu 
'fumaça' > igogo, *utu 'mofo' > utun 'cogumelo' segundo Ladhams (2007)) e 1 item (2,22\%) apresenta étimo desconhecido até o momento, não sendo possível estabelecer se houve a realização do processo. No conjunto de exemplos em (6), (6.a), (6.b), (6.c) e (6.d) ilustram o processo de aglutinação de vogal inicial em PGG, enquanto os exemplos em (6.e), (6.f), (6.g), (6.h) demonstram a manutenção da vogal inicial do étimo português e os em (6.i) e (6.j) a manutenção da vogal inicial de procedência edoide:

(a) 'pé' ou 'perna' > *ope

(b) 'joelho' $>*$ ozoko

(c) 'mar' $>*^{*}$ omali

(d) 'pó' > *opo

(e) 'osso' $>$ *oso

(f) 'hoje' $>*$ oz

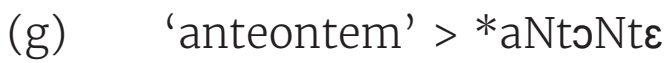

(h) 'altar' > *altali

(i) Ize 'camarão' > *ize

(j) Idu 'piolho' > *idu

Dessa forma, assim como nas protoformas verbais, o processo de aglutinação de vogal inicial não parece ter sido produtivo entre as protoformas não verbais.

Uma hipótese de que a aglutinação de vogal pudesse ser motivada por uma tendência do PGG a evitar elementos clíticos não parece ser muito forte, pois se esse fosse o caso se esperaria uma maior produtividade no processo. Ademais, é possível encontrar clíticos como categoria pronominal e preposição: na reconstrução gramatical do PGG, reconstruiu-se, por exemplo, a primeira pessoa do singular $*_{n}$ na posição de sujeito $e^{*} m$ na posição de possessivo, assim como a preposição *ku (BANDEIRA \& ARAUJO, em preparação).

Visando observar se algum tipo de comprimento (em número de sílabas) estaria sendo privilegiado pela gramática do PGG, apresentamos na Tabela 3 a distribuição das protoformas não verbais do PGG de acordo com sua constituição em número de sílabas: 
V. $10(1)$

$232-255$

jan-abr 2020

Tabela 3 - Distribuição de protoformas não verbais do PGG por número de sílabas

\begin{tabular}{cc}
\hline Número de sílabas $(\boldsymbol{\sigma})$ & Não verbos \\
Monossílabos $(1 \sigma)$ & $12(3,04 \%)$ \\
Dissílabos $(2 \sigma)$ & $243(61,52 \%)$ \\
Trissílabos $(3 \sigma)$ & $113(28,61 \%)$ \\
Polissílabos $(4 \sigma)$ & $12(3,04 \%)$ \\
Palavras compostas & $15(3,80 \%)$ \\
TOTAL & $395(100 \%)$ \\
\hline Fonte: Elaborada pelas autoras.
\end{tabular}

Como mostram os resultados na Tabela 3, 61,52\% das protoformas nominais são constituídas por duas sílabas. Em segundo lugar, aparecem aquelas formadas por três sílabas, que somam 28,61\% dos itens nominais do PGG. Novamente, itens constituídos por uma e quatro sílabas não são expressivos, correspondendo a 3,04\% cada.

Ao analisarmos os 243 itens nominais dissílabos do PGG, verificamos que $170(69,96 \%)$ deles já apresentavam essa constituição no étimo português, de modo que, mesmo sendo interpretados pela fonologia do PGG, não houve mudança quanto à sua constituição em número de sílabas. Assim, não parece haver uma restrição que motive o comprimento das palavras prosódicas em número de sílabas.

Ainda sobre as protoformas nominais constituídas por duas sílabas, verificamos que $40(16,46 \%)$ eram constituídas por três sílabas no étimo português, sofrendo apagamento e ressilabificação ao serem interpretadas pelo PGG, integrando o léxico dessa protolíngua como itens constituídos por duas sílabas. É o caso de *bana 'banana' e *klosu 'caroço', por exemplo.

Embora apenas 3,04\% das protoformas não verbais do PGG sejam constituídas por uma única sílaba, dois fatos chamam-nos a atenção: (i) parte desses itens serem monossílabos no étimo português, de modo que o processo de aglutinação de vogal inicial parece não ter sido engatilhado por qualquer monossílabo, e (ii) parte dos itens monossilábicos em PGG apresentarem ditongos crescentes. Em (7), apresentamos as protoformas não verbais constituídas por uma sílaba que ilustram esses casos: 
(7)

(a) 'pão' > *poN

(b) 'mão' > *moN

(c) 'rua' > *lwa

(d) 'dia' $>*$ dja

(e) 'folha' $>*$ fja

Os itens (7.a) e (7.b) apresentam constituição monossilábica tanto em PGG quanto no étimo português. Conforme discutido anteriormente, o input português na época da formação do PGG pode ter sido idêntico à forma assumida pelo item nessa protolíngua, por não violar a fonologia da gramática que ali se formava. Nota-se que tais itens são constituídos por uma sílaba pesada, visto que a posição de coda está preenchida, o que pode ter bloqueado o processo de aglutinação de vogal inicial.

Os itens (7.c) e (7.d), por sua vez, eram realizados como monossílabos portadores de ditongos, em português arcaico: Zucarelli (2004, p. 35), analisando os encontros vocálicos em cantigas de amor e de amigo, chega à conclusão de que os ditongos crescentes em português arcaico correspondiam a hiatos em sua forma subjacente, mas que eram realizados como uma única sílaba poética, de acordo com a análise da métrica utilizada pelos trovadores portugueses. Dessa forma, o input português que teve participação na formação do PGG provavelmente trouxe tais itens lexicais como monossílabos com ditongos crescentes, caracterizando-os como sílabas leves, mas com uma estrutura CCV.

Já (7.e) parece ser o resultado do enfraquecimento da vogal ' $o$ ' ao ponto desta sofrer apagamento, que seria seguido da redução da consoante palatal ' $h$ ' e da sua realização como aproximante ' $j$ '.

Ademais, observamos que, das 12 protoformas reconstruídas para o PGG como sendo constituídas por uma única sílaba, oito assumiram tal constituição ao passarem por processos fonológicos e regras fonotáticas do PGG. Ou seja, itens que em seu étimo eram dissílabos, ao entrarem no PGG passaram a ser monossílabos. Dessa forma, não parece ter havido uma regra de eurritmia aplicada, quanto ao número de sílabas, ao domínio da palavra prosódica na formação do léxico do PGG. 
V. 10 (1) 232-255 jan-abr 2020

\section{Considerações finais}

Nossa análise se baseou numa ideia apresentada por Bandeira (2017) de que poderia haver no PGG alguma motivação inerente ao seu sistema e que fosse engatilhada por aspectos prosódicos da língua que motivassem a criação de palavras dissílabas ou mesmo trissílabas. A partir disso, levantamos a hipótese de que questões de eurritmia no domínio da palavra prosódica, respeitando a constituição de uma palavra prosódica mínima, pudessem ser importantes para a constituição dos itens lexicais do PGG, favorecendo um determinado comprimento.

Entretanto, enquanto autores como Landhams (2007) e Hagemeijer (2009b) têm observado um número considerável de ocorrências do fenômeno de aglutinação de vogal inicial nas línguas filhas, em especial em lung'Ie, após analisarmos quantitativamente os vários tipos de constituição (em número de sílabas) das palavras prosódicas do PGG reconstruídas, assim como do input português e edo que tenha contribuído na formação do PGG, verificamos que as hipóteses levantadas não se sustentam e que essa aglutinação de vogal inicial, encontrada em poucos itens do PGG, parece ter sido um processo marginal. A ampla ocorrência do processo em lung' Ie, portanto, ocorreu durante sua especiação, provavelmente graças a um maior acesso a um input de línguas edoides, conforme argumenta Landhams (2007, p. 5).

Assim, concluímos que o sistema fonológico e prosódico do PGG possibilitou a constituição de palavras tanto com mais quanto com menos sílabas do que no étimo português que participou de sua formação, sem parecer privilegiar um tipo de formação de palavra levando em conta apenas seu comprimento em número de sílabas. Observamos, porém, que parece haver uma restrição que evite que verbos sejam iniciados por vogais, o que de alguma forma parece dialogar com a restrição encontrada nas línguas edoides (que participaram da formação do PGG), de que palavras nominais sejam iniciadas por segmentos vocálicos.

Em análises futuras, pretendemos expandir o estudo para as línguas-filhas, em especial o lung'Ie, buscando verificar em que medida critérios prosódicos podem ter participado do processo de aglutinação de vogal em início de palavra, tendo em vista que essa seria a língua do Golfo da Guiné em que de fato o processo seria produtivo, de acordo com a literatura. 


\section{Referências}

AGOSTINHO, A. L. S. Fonologia e método pedagógico do lung'Ie. 2015. Tese (Doutorado em Letras) - Faculdade de Filosofia, Letras e Ciências Humanas, Universidade de São Paulo, São Paulo.

ARAUjO, G.; HAGEMEIJER, T. Dicionário Santome-Português/ Português-Santome. São Paulo: Hedra, 2013.

BANDEIRA, M. Reconstrução fonológica e lexical do protocrioulo do Golfo da Guiné. 2017. Tese (Doutorado em Letras) - Faculdade de Filosofia, Letras e Ciências Humanas, Universidade de São Paulo, São Paulo. doi:10.11606/T.8.2017.tde-05042017-134159.

BANDEIRA, M.; ARAUJO, G. Reconstrução do quadro pronominal do protocrioulo do Golfo da Guiné. Em preparação.

BARRENA, N. Gramatica anobonesa. Madrid: Instituto de Estudios Africanos, 1957.

CAMPBELL, Lyle. Historical linguistics: an introduction. Edinburgh: Edinburgh University Press, 2004 [1998].

FERRAZ, L. I. The creole of São Tomé. Johannesburg: Witwatersrand University Press, 1979.

GARFIELD, R. A history of São Tomé island: 1470-1655. The key to Guinea. San Francisco: Mellen Research University Press, 1992.

GHINI, M. F-formation in Italian: a new proposal. In: DYCK, C. (ed.). Toronto working papers in linguistics. Toronto: Universityof Toronto, V. 12, n. 2, p.41-78, 1993.

HAGEMEIJER, T. As línguas de São Tomé e Príncipe, Revista de Crioulos de Base Lexical Portuguesa e Espanhola, V.1, p. 1-29. 2009 a.

HAGEMEIJER, T. Initial vowel agglutination in the Gulf of Guinea creoles. In: $\mathrm{ABOH}$, Enoch Oladé; SMITH, Norval (Eds.). Complex processes in the new languages. Creole Language Library, v. 35.Amsterdam/ Philadelphia: John Benjamins Publishing Company, p. 29-50, $2009 \mathrm{~b}$.

HLIBOWICKA-WEGGLARZ, B. A origem dos crioulos de base lexical portuguesa no Gólfo da Guiné. Romanica Cracoviensia, Kraków, v.11, p. 177-185, 2012. Disponível em: <http://www.wuj.pl/UserFiles/File/ Romanica\%20Cracoviensia\%202011/23-Hlibowicka-RC-2011.pdf $>$. Acesso em: 28 jun. 2016.

HOLM, J. Pidgins and creoles. v. 2. Cambridge: Cambridge University Press, 1989.

LADHAMS, J. Agglutination and the African Contribution to the Portuguese-based Creoles, 2007. Disponível em:<https://www.google. it $/ z$ ? sa $=t \& r c t=j \& q=\&$ esrc $=s \&$ source $=$ web \& $c d=1 \& c a d=r j a \& u a c t=8 \& v e d=$ oahUKEwi6zKmvtPHPAhWDxxQKHaPoA1YQFgggMAA\&url=http\%3A\% 2F>. Acesso em: 20 out. 2016. 
V. 10 (1) 232-255 jan-abr 2020

MAURER, P. L'Angolar: Un créole afroportugais parlé à São Tomé; Notes de grammaire, textes, vocabulaires. Hamburg: Helmut BuskeVerlag, 1995.

MAURER, P. Lung'Ie. Londres: BattlebridgePublications, 2009.

MASSINI-CAGLIARI, G. Epêntese e paragoge: processos fonológicos distintos. In: CONGRESSO INTERNACIONAL DA ABRALIN, 2., e INSTITUTO LINGÚÍSTICO, 2000, Florianópolis, Anais... Florianópolis: ABRALIN - Associação Brasileira de Lingüística. p.400-410, 2000. CDROM.

SCHANG, E. L'émergence des creoles portugais du Golfe de Guinée. 2000. Tese de doutorado. Université de Nancy 2.

SEGORBE, A. Gramática descriptiva del fa d'ambô. Barcelona: CEIBA Ediciones, 2007.

TEYSSIER, P. História da língua portuguesa. $4^{\mathrm{a}}$. Ed. São Paulo: Martins Fontes, 2014.

VIGÁRIO, M. The prosodic word in European Portuguese. Berlin-New York: Mouton de Gruyter, 2003.

ZUCARELLI, F. L. Encontros vocálicos em português arcaico: uma interpretação fonológica, Alfa, São Paulo, v. 43, n. 1, p. 29-48. 2004. 


\section{Errata}

Relacionada a DOI: 10.22168/2237-6321-11722

BRAGA, Gabriela; BANDEIRA, Manuele. Ritmo e peso silábico na constituição das palavras prosódicas do protocrioulo do Golfo da Guiné. Entrepalavras, Fortaleza, v. 10, n. 1, ahead of print, jan-abr/2019. DOI: 10.22168/2237-6321-11722.

A revista recebeu solicitação de retirada do nome de um dos autores. A autoria correta é:

\section{Gabriela Braga}

BRAGA, Gabriela. Ritmo e peso silábico na constituição das palavras prosódicas do protocrioulo do Golfo da Guiné. Entrepalavras, Fortaleza, v. 10, n. 1, ahead of print, jan-abr/2019. DOI: 10.22168/2237-632111722 .

A revista foi informada de alteração na nota de rodapé 1 . A nota de rodapé 1 correta é:

O presente trabalho foi realizado com apoio da seguinte instituição de fomento à pesquisa: Coordenação de Aperfeiçoamento de Pessoal de Nível Superior - Brasil (CAPES) - Código de Financiamento o01.

O título A influência de características rítmicas e do peso silábico na constituição das palavras prosódicas do protocrioulo do Golfo da Guiné, por solicitação da revista e sugestão dos autores, foi alterado para Ritmo e peso silábico na constituição das palavras prosódicas do protocrioulo do Golfo da Guiné. 